\title{
Laryngeal and hypopharyngeal cancers and occupational exposure to formaldehyde and various dusts: a case-control study in France
}

Laurent Laforest, Danièle Luce, Paquerette Goldberg, Denis Bégin, Michel Gérin, Paul A Demers, Jacques Brugère, Annette Leclerc

\begin{abstract}
Objectives-A case-control study was conducted in France to assess possible associations between occupational exposures and squamous cell carcinomas of the larynx and hypopharynx.

Methods-The study was restricted to men, and included 201 hypopharyngeal cancers, 296 laryngeal cancers, and 296 controls (patients with other tumour sites). Detailed information on smoking, alcohol consumption, and lifetime occupational history was collected. Occupational exposure to seven substances (formaldehyde, leather dust, wood dust, flour dust, coal dust, silica dust, and textile dust) was assessed with a job exposure matrix. Exposure variables used in the analysis were probability, duration, and cumulative level of exposure. Odds ratios (ORs) with their $95 \%$ confidence intervals (95\% CIs) were estimated by unconditional logistic regression, and were adjusted for major confounding factors (age, smoking, alcohol, and when relevant other occupational exposures).
\end{abstract}

Results-Hypopharyngeal cancer was found to be associated with exposure to coal dust (OR 2.31, 95\% CI 1.21 to 4.40 ), with a significant rise in risk with probability $(p<0.005$ for trend) and level $(p<0.007$ for trend) of exposure. Exposure to coal dust was also associated with an increased risk of laryngeal cancer (OR $1.67,95 \%$ CI 0.92 to 3.02 ), but no doseresponse pattern was found. A significant relation, limited to hypopharyngeal cancer, was found with the probability of exposure to formaldehyde $(p<0.005$ for trend), with a fourfold risk for the highest category (OR $3.78,95 \%$ CI 1.50 to 9.49 ). When subjects exposed to formaldehyde with a low probability were excluded, the risk also increased with duration $(p<0.04)$ and cumulative level of exposure $(p<0.14)$. No significant association was found for any other substance.

Conclusion-These results indicate that exposure to formaldehyde and coal dust may increase the risk of hypopharyngeal cancer.

(Occup Environ Med 2000;57:767-773)

Keywords: laryngeal cancer; hypopharyngeal cancer; occupational exposure; job exposure matrix; formaldehyde; coal dust
The highest age adjusted incidences of laryngeal and hypopharyngeal cancers in Europe are found in France.

Numerous epidemiological studies have sought to identify aetiological factors for these cancers. Smoking and alcohol consumption are well established as major risk factors. ${ }^{2}{ }^{3}$ Smoking and drinking combined seem to have a multiplicative effect. ${ }^{4}$ Several studies suggest that some dietary constituents could influence laryngeal and pharyngeal tumours. ${ }^{6}$

Studies have also assessed some of the occupational exposures that might increase the risk of these cancers. The indicators of occupational exposure most often used have been job titles or industrial sectors. Increased risks have been reported for several occupational groups, including textile workers,,${ }^{7-9}$ metal processors, ${ }^{10}$ coal miners, ${ }^{7}$ mechanics, ${ }^{11}{ }^{12}$ and machinists. ${ }^{13}$ Although the association between exposure to asbestos and laryngeal cancer has been repeatedly found, the existence of a causal relation is still debated. ${ }^{14-19}$ Occupational exposure to polycyclic aromatic hydrocarbons ${ }^{20}$ has also been suspected. Several studies have found an increased risk of laryngeal cancer among workers exposed to sulphuric acid. ${ }^{21-23}$ No definitive conclusions can be drawn about the association between laryngeal or hypopharyngeal cancer and occupational exposures to wood dust or formaldehyde. ${ }^{24}$ Most epidemiological examinations of occupational factors have, overall, yielded results that are either non-significant or require further investigation for confirmation.

A case-control study in France examined occupational risk factors for laryngeal and hypopharyngeal cancers. Previous reports from this study have analysed associations with job titles and industrial sectors, ${ }^{25}$ and with asbestos and man made vitreous mineral fibres. ${ }^{26}$ The present paper deals with the possible association between these two cancer sites and exposure to formaldehyde, leather dust, wood dust, textile dust, flour dust, coal dust, and silica dust.

\section{Material and methods}

STUDY POPULATION

Cases were male patients with incident primary laryngeal and hypopharyngeal squamous cell cancers, diagnosed and histologically confirmed in 15 French hospitals between 1 January 1989 and 30 April 1991. Because of the paucity of other histological types (less than $1 \%$ ), only squamous cell cancers were considered, and because of the low incidence of 
hypopharyngeal and laryngeal tumours among women, only men were recruited. The study initially identified 664 patients meeting these criteria. Of these, $136(20.5 \%)$ could not be interviewed because of health problems $(n=40)$, death before an interview could be conducted $(n=11)$, refusal to participate $(n=22)$, or because they could not be located $(n=63)$. In all, the study finally included 206 men with hypopharyngeal cancer, 315 with laryngeal cancer, and seven with cancers of both the larynx and hypopharynx. Controls were patients with primary cancers of different sites, selected by frequency matching on age and recruited between 1987 and 1991 in the same hospitals as the cases or in similar hospitals nearby. The aim was to obtain a control group of the same size as the group of cases of laryngeal cancer. Of the 355 controls identified, $50(14 \%)$ could not be interviewed, because of medical conditions $(n=14)$, refusal $(n=14)$, or because they could not be located $(n=22)$. To obtain comparable catchment areas, controls were patients with cancers requiring the same medical environment as the cases. The following sites were selected: rectum or anal canal $(n=30)$, liver or gall bladder $(n=15)$, pancreas $(n=11)$, haematopoietic system $(n=34)$, bones and cartilage $(n=7)$, skin (melanoma) $(n=18)$, soft tissue $(n=11)$, prostate $(n=63)$, testis $(n=17)$, bladder $(n=29)$, other urinary organs $(n=27)$, brain and nervous system $(n=18)$, thyroid $(n=18)$, colon $(\mathrm{n}=5)$, and stomach $(\mathrm{n}=2)$.

Occupational physicians specially trained for this study interviewed both cases and controls and collected detailed data about demographic characteristics, alcohol and tobacco consumption, and lifetime occupational history. A more complete description of the study design and of the characteristics of cases and controls has previously been published. ${ }^{25}$

Of the 833 subjects included in the study, some were excluded from the analysis: those with cancer at more than one site $(n=7)$, those who did not answer the questions on alcohol (five cases of laryngeal cancer), and those who did not drink at all (nine controls, 14 cases of laryngeal cancer, five cases of hypopharyngeal cancer, because it was unclear whether they were teetotal or former drinkers who had stopped for health reasons). The final analysis thus included 793 subjects: 296 controls, 201 men with hypopharyngeal cancer, and 296 with laryngeal cancer. Those with laryngeal cancer were divided into anatomical subsites according to the classification used by Tuyns et $a l .{ }^{4}$ These sites were the epilarynx $(\mathrm{n}=97)$, the glottis $(n=102)$, the supraglottis $(n=80)$, the subglottis $(n=3)$, and larynx unspecified $(\mathrm{n}=14)$.

\section{OCCUPATIONAL EXPOSURES}

Each job was coded with standard classification for occupation (ISCO) ${ }^{27}$ and industry (ISIC). ${ }^{28}$ Occupational exposures were assessed through a job exposure matrix (JEM), developed earlier by three of the authors (PD for wood and leather dust, $\mathrm{DB}$ and $\mathrm{MG}$ for other substances) for a study on sinonasal cancer ${ }^{29}$ (the JEM is available from the authors).

For each ISCO-ISIC combination and for each substance, the JEM gives the probability of exposure, and the level of exposure in categories. The cut off points used for the categories of level and probability, according to the substance, are presented in table 1 . When the probability of exposure was less than $10 \%$ (for wood dust and leather dust) or less than $1 \%$ (for the other substances), the job was considered to be unexposed.

For a given substance, for each job i of each subject, the JEM provides the probability of exposure $\mathrm{P}_{\mathrm{i}}$ and the level of exposure $\mathrm{L}_{\mathrm{i}}$. The job duration $\mathrm{D}_{\mathrm{i}}$ was also available. Subjects could have had several successive jobs i exposed to the same substance throughout their working life. Several exposure variables were calculated to summarise the subject's lifetime exposure: maximum probability of exposure $=\max \left(\mathrm{P}_{\mathrm{i}}\right)$; total duration of exposure (in years) $=\Sigma \mathrm{D}_{\mathrm{i}} ;$ cumulative level of exposure $=\Sigma \mathrm{L}_{\mathrm{i}} \mathrm{P}_{\mathrm{i}} \mathrm{D}_{\mathrm{i}}$.

To calculate the cumulative level, quantitative values (midpoints of the intervals) were assigned to each category of level and probability (table 1).

\section{DATA ANALYSIS}

Each substance was studied independently. Separate analyses were conducted for cancers of the larynx and hypopharynx. Each analysis used the same control group.

Occupational exposure was first assessed by a dichotomous variable ever versus never exposed. Quantitative exposure variables were converted into categorical variables according to their distribution among all subjects. The number of classes ranged from two to four, depending on the frequency of exposure. The reference category for each analysis was the never exposed subjects.

Table 1 Categories for level and probability of exposure defined in the $\mathcal{F E M}$ for the studied substances and assigned values

\begin{tabular}{|c|c|c|c|c|}
\hline \multirow[b]{2}{*}{ Substances } & \multicolumn{2}{|c|}{ Level categories } & \multicolumn{2}{|c|}{ Probability categories } \\
\hline & $\begin{array}{l}\text { Cut off } \\
\text { points }\end{array}$ & $\begin{array}{l}\text { Assigned } \\
\text { value }\end{array}$ & $\begin{array}{l}\text { Cut off } \\
\text { points } \\
(\%)\end{array}$ & $\begin{array}{l}\text { Assigned } \\
\text { value }\end{array}$ \\
\hline \multirow[t]{3}{*}{ Leather dust } & Low & 1.00 & $10-50$ & 0.30 \\
\hline & Medium & 2.00 & $50-90$ & 0.70 \\
\hline & High & 3.00 & $>90$ & 1.00 \\
\hline \multirow[t]{3}{*}{ Wood dust } & $<1$ & 0.50 & $10-50$ & 0.30 \\
\hline & $1-5$ & 3.00 & $50-90$ & 0.70 \\
\hline & $>5$ & 9.00 & $>90$ & 1.00 \\
\hline \multirow{4}{*}{ Formaldehyde } & $<0.25$ & 0.15 & $1-10$ & 0.05 \\
\hline & $0.25-1.00$ & 0.65 & $10-50$ & 0.30 \\
\hline & $>1.00$ & 3.00 & $50-90$ & 0.70 \\
\hline & & & $>90$ & 1.00 \\
\hline \multirow[t]{3}{*}{ Flour dust } & $<0.5$ & 0.25 & $1-10$ & 0.05 \\
\hline & $0.5-5$ & 3.00 & $10-90$ & 0.50 \\
\hline & $>5$ & 10.0 & $>90$ & 1.00 \\
\hline \multirow[t]{3}{*}{ Coal dust } & $<0.3$ & 0.15 & $1-10$ & 0.05 \\
\hline & $0.3-2$ & 1.20 & $10-90$ & 0.50 \\
\hline & $>2$ & 5.00 & $>90$ & 1.00 \\
\hline \multirow{3}{*}{ Silica } & $<0.01$ & 0.005 & $1-10$ & 0.05 \\
\hline & $0.01-0.1$ & 0.050 & $10-90$ & 0.50 \\
\hline & $>0.1$ & 0.200 & $>90$ & 1.00 \\
\hline \multirow[t]{3}{*}{ Textile dust } & $<0.05$ & 0.025 & $1-10$ & 0.05 \\
\hline & $0.05-0.5$ & 0.250 & $10-90$ & 0.50 \\
\hline & $>0.5$ & 1.500 & $>90$ & 1.00 \\
\hline
\end{tabular}

*Wood dust, flour dust, coal dust, silica, textile dust $\left(\mathrm{mg} / \mathrm{m}^{3}\right)$, and formaldehyde (ppm). 
The analysis used multivariate unconditional logistic regression, performed with SAS software. Adjusted odds ratios (ORs) are reported with their $95 \%$ confidence intervals ( $95 \%$ CIs). All ORs were adjusted for age $(<60 ; \geqslant 60)$, alcohol ( $0-4$ glasses/day; $\geqslant 5$ glasses/day) and smoking (<30 pack-years; $\geqslant 30$ pack-years). Preliminary analysis showed that with a finer stratification for age ( $\leqslant 49$ years, 50-59, 60-69, $>69$ ), alcohol ( $\leqslant 2$ glasses/day, 3-4, 5-8, 9-12, $\geqslant 13$ ) and smoking (non-smoker, 1-29 packyears, $30-44, \geqslant 45$ ) did not substantially alter the adjusted ORs for occupational exposures.

Other occupational exposures (including asbestos and man made mineral fibres) and education level (primary school or less, higher than primary school) were considered to be possible confounders for any given substance and were included in the final model if more than 10 subjects (cases or controls) were exposed to both the substance under consideration and the potential confounder, and if the confounder changed the OR estimate by more than $10 \%$. When a dose-response pattern of interest was found for a categorised exposure variable, a test for trend was performed by assigning the score $\mathrm{k}$ to the $\mathrm{kth}$ level of exposure (the number 0 was assigned to the reference category) and entering the score into logistic models. We also examined more complex logistic models including interaction terms between occupational exposures and age, and alcohol and tobacco consumption.

For substances other than wood dust and leather dust, further analyses were performed by excluding subjects considered to be exposed with a probability of exposure less than $10 \%$.

We also analysed the data according to laryngeal subsites, and we compared, for each substance, the risk of cancer of the epilarynx with that of cancer of other parts of the larynx (endolarynx) and the hypopharynx.

To allow for a possible induction period, successive analyses excluded the 5, 10, and 15 years of exposure immediately before the reference date (cancer diagnosis).

In all additional analyses, the ORs were adjusted for the variables found to be confounders in the earlier analyses.

Table 2 Education level, age, and alcohol and tobacco consumption for cases and controls

\begin{tabular}{|c|c|c|c|c|c|c|}
\hline & \multicolumn{4}{|l|}{ Cases } & & \\
\hline & \multicolumn{2}{|c|}{ Larynx } & \multicolumn{2}{|c|}{ Hypopharynx } & \multicolumn{2}{|c|}{ Controls } \\
\hline & $n$ & $\%$ & $n$ & $\%$ & $n$ & $\%$ \\
\hline \multicolumn{7}{|l|}{ Education: } \\
\hline Primary & 169 & 57.0 & 128 & 63.7 & 134 & 45.2 \\
\hline More than primary & 127 & 43.0 & 73 & 32.3 & 162 & 54.8 \\
\hline \multicolumn{7}{|l|}{ Age $(y)$ : } \\
\hline $0-59$ & 148 & 50.0 & 127 & 63.2 & 141 & 47.6 \\
\hline$\geqslant 60$ & 148 & 50.0 & 74 & 36.8 & 155 & 52.4 \\
\hline \multicolumn{7}{|c|}{ Alcohol consumption (glasses/day): } \\
\hline $0-4$ & 99 & 33.4 & 45 & 22.4 & 172 & 58.1 \\
\hline$\geqslant 5$ & 197 & 66.6 & 156 & 77.6 & 124 & 41.9 \\
\hline \multicolumn{7}{|c|}{ Tobacco smoking (pack-years): } \\
\hline $0-29$ & 78 & 26.3 & 51 & 25.4 & 195 & 65.9 \\
\hline$\geqslant 30$ & 218 & 73.7 & 150 & 74.6 & 101 & 34.1 \\
\hline Total & 296 & 100 & 201 & 100 & 296 & 100 \\
\hline
\end{tabular}

\section{Results}

Table 2 summarises the principal characteristics of each of the study groups for education level, age, daily alcohol consumption, and smoking.

Table 3 reports the number of exposed subjects and the adjusted OR for each substance. Only 19 workers $(2.4 \%$ of all subjects) were exposed to leather dust; therefore no further analysis was performed for it. Exposure was most frequent for formaldehyde $(n=270$, $34.0 \%)$ and silica dust $(n=326,41.1 \%)$. The frequency of exposure to the other substances was $8.1 \%$ for textile dust $(n=64), 13.4 \%$ for coal dust $(n=106), 14.6 \%$ for wood dust $(n=116)$, and $7.2 \%$ for flour dust $(n=57)$.

An increased risk of hypopharyngeal cancer, although not significant, was found for exposure to formaldehyde. There was a clear doseresponse pattern with the probability of exposure (trend test $\mathrm{p}<0.005$ ). No significant trend was noted, however, with duration or cumulative level of exposure. Exposure to formaldehyde also slightly increased the risk of laryngeal cancer, but there was no indication of a dose-response trend (table 3 ).

The ORs associated with exposure to coal dust (ever or never) were increased for both cancer sites. For hypopharyngeal cancer, dose response relations were found with cumulative level (trend test: $\mathrm{p}<0.005$ ), and probability of exposure ( $p<0.007$ for trend).

None of the other substances-leather dust, wood dust, flour dust, textile dust and silica dust - was significantly associated with either cancer site, nor were any trends found.

Interaction terms between occupational exposures and age, alcohol, or smoking were generally non-significant. Nevertheless, there was an indication of an association between formaldehyde and laryngeal cancer limited to heavy drinkers. Exposure to formaldehyde was associated with a non-significantly decreased risk among drinkers of less than five glasses a day (OR $0.66,95 \%$ CI 0.35 to 1.25 ), whereas it was associated with an increased risk of laryngeal cancer among heavy drinkers (OR 1.68, $95 \%$ CI 0.97 to 2.89 ). However, when a more detailed analysis was performed to investigate the association between formaldehyde and laryngeal cancer among heavy drinkers, no dose-response trend was found with probability, duration, or level of exposure. There was no interaction between alcohol and formaldehyde for hypopharyngeal cancer. The presence of an interaction between formaldehyde and coal dust was also tested and found to be nonsignificant.

After exposed subjects with a low probability of exposure $(<10 \%)$ were excluded, the ORs associated with exposure to formaldehyde and coal dust increased (table 4).

Exposure to formaldehyde was associated with an increased risk of hypopharyngeal cancer, and the risk increased with duration $(p<0.04)$ and cumulative level of exposure $(\mathrm{p}<0.14)$. Neither the ORs nor any trend suggested an association with laryngeal cancer.

The association between coal dust and hypopharyngeal cancer was significant, and the 
Table 3 Risk of cancer of the larynx and hypopharynx, by occupational exposure to each substance

\begin{tabular}{|c|c|c|c|c|c|c|}
\hline & \multicolumn{3}{|l|}{ Larynx } & Hypopharynx & & \\
\hline & Cases/ controls & Adjusted $O R$ & $95 \% C I$ & Cases/ controls & Adjusted $O R$ & $95 \% C I$ \\
\hline Leather dust: & & & & & & \\
\hline Never exposed & $288 / 288$ & 1.00 & - & $198 / 288$ & 1.00 & - \\
\hline Ever exposed & $8 / 8$ & 0.89 & 0.62 to 1.27 & $3 / 8$ & 0.80 & 0.16 to 4.07 \\
\hline Wood dust ${ }^{\star}$ : & & & & & & \\
\hline Never exposed & $249 / 260$ & 1.00 & - & $168 / 260$ & 1.00 & - \\
\hline Ever exposed & $47 / 36$ & 1.00 & 0.58 to 1.72 & $33 / 36$ & 0.89 & 0.47 to 1.68 \\
\hline Probability of exposure $(\%$ & & & & & & \\
\hline$\leqslant 70$ & $20 / 18$ & 0.92 & 0.44 to 1.95 & $11 / 18$ & 0.69 & 0.28 to 1.76 \\
\hline$>70$ & $27 / 18$ & 1.08 & 0.53 to 2.21 & $22 / 18$ & 1.06 & 0.48 to 2.31 \\
\hline Duration of exposure $(y)$ : & & & & & & \\
\hline$<6$ & $21 / 12$ & 1.41 & 0.62 to 3.20 & $10 / 12$ & 0.53 & 0.19 to 1.51 \\
\hline $6-10$ & $7 / 11$ & 0.49 & 0.17 to 1.48 & $10 / 11$ & 1.00 & 0.34 to 2.91 \\
\hline$>10$ & $19 / 13$ & 1.03 & 0.46 to 2.30 & $13 / 13$ & 1.19 & 0.48 to 2.95 \\
\hline Cumulative level: & & & & & & \\
\hline Low $(<10)$ & $20 / 14$ & 0.97 & 0.44 to 2.14 & $10 / 14$ & 0.56 & 0.20 to 1.56 \\
\hline Medium (10-42) & $15 / 13$ & 1.16 & 0.49 to 2.75 & $8 / 13$ & 0.74 & 0.25 to 2.25 \\
\hline $\operatorname{High}(>42)$ & $12 / 9$ & 0.86 & 0.33 to 2.28 & $15 / 9$ & 1.52 & 0.59 to 3.94 \\
\hline Formaldehydef: & & & & & & \\
\hline Never exposed & $194 / 211$ & 1.00 & - & $118 / 211$ & 1.00 & - \\
\hline Ever exposed & $102 / 85$ & 1.14 & 0.76 to 1.70 & $83 / 85$ & 1.35 & 0.86 to 2.14 \\
\hline Probability of exposure (\% & & & & & & \\
\hline$<10$ & $58 / 50$ & 1.16 & 0.73 to 1.86 & $42 / 50$ & 1.08 & 0.62 to 1.88 \\
\hline $10-50$ & $23 / 20$ & 1.12 & 0.55 to 2.30 & $15 / 20$ & 1.01 & 0.44 to 2.31 \\
\hline$>50$ & $21 / 15$ & 1.04 & 0.44 to 2.47 & $26 / 15$ & 3.78 & 1.50 to 9.49 \\
\hline Duration of exposure (y): & & & & & & \\
\hline$<7$ & $35 / 22$ & 1.42 & 0.75 to 2.68 & $18 / 22$ & 1.09 & 0.50 to 2.38 \\
\hline $7-20$ & $37 / 31$ & 1.09 & 0.62 to 1.96 & $37 / 31$ & 1.39 & 0.74 to 2.62 \\
\hline$>20$ & $30 / 32$ & 0.96 & 0.52 to 1.76 & $28 / 32$ & 1.51 & 0.78 to 2.92 \\
\hline Cumulative level: & & & & & & \\
\hline Low $(<0.02)$ & $35 / 29$ & 1.12 & 0.62 to 2.01 & $23 / 29$ & 1.03 & 0.51 to 2.07 \\
\hline Medium $(0.02-0.09)$ & $38 / 26$ & 1.44 & 0.79 to 2.63 & $32 / 26$ & 1.57 & 0.81 to 3.06 \\
\hline High $(>0.09)$ & $29 / 30$ & 0.87 & 0.45 to 1.67 & $28 / 30$ & 1.51 & 0.74 to 3.10 \\
\hline Flour dust $\ddagger$ : & & & & & & \\
\hline Never exposed & $274 / 282$ & 1.00 & - & $180 / 282$ & 1.00 & - \\
\hline Ever exposed & $22 / 14$ & 1.52 & 0.69 to 3.34 & $21 / 14$ & 1.92 & 0.82 to 4.50 \\
\hline Probability of exposure (\% & & & & & & \\
\hline$\leqslant 90$ & $5 / 1$ & 8.00 & 0.84 to 75.8 & $5 / 1$ & 22.1 & 2.15 to 226 \\
\hline$>90$ & $17 / 13$ & 1.11 & 0.47 to 2.60 & $16 / 13$ & 1.16 & 0.46 to 2.91 \\
\hline Duration of exposure (y): & & & & & & \\
\hline$\leqslant 3$ & $9 / 6$ & 2.22 & 0.70 to 7.08 & $8 / 6$ & 2.61 & 0.76 to 9.01 \\
\hline$>3$ & $13 / 8$ & 1.15 & 0.43 to 1.28 & $13 / 8$ & 1.53 & 0.53 to 4.44 \\
\hline Cumulative level: & & & & & & \\
\hline Low $(<20)$ & $10 / 8$ & 1.45 & 0.50 to 4.22 & $13 / 8$ & 2.25 & 0.78 to 6.53 \\
\hline High $(>20)$ & $12 / 6$ & 1.59 & 0.54 to 4.70 & $8 / 6$ & 1.51 & 0.42 to 5.38 \\
\hline Textile dust $\$:$ & & & & & & \\
\hline Never exposed & $272 / 275$ & 1.00 & - & $182 / 275$ & 1.00 & - \\
\hline Ever exposed & $24 / 21$ & 1.22 & 0.61 to 2.43 & $19 / 21$ & 1.63 & 0.74 to 3.60 \\
\hline Probability of exposure (\% & & & & & & \\
\hline$\leqslant 90$ & $8 / 10$ & 0.98 & 0.33 to 2.85 & $10 / 10$ & 2.13 & 0.74 to 6.14 \\
\hline$>90$ & $16 / 11$ & 1.41 & 0.58 to 3.44 & $9 / 11$ & 1.21 & 0.39 to 3.72 \\
\hline Duration of exposure (y): & & & & & & \\
\hline$<7$ & $15 / 7$ & 2.07 & 0.75 to 5.74 & $11 / 7$ & 2.20 & 0.70 to 6.91 \\
\hline$\geqslant 7$ & $9 / 14$ & 0.74 & 0.28 to 1.95 & $8 / 14$ & 1.26 & 0.43 to 3.65 \\
\hline Cumulative level: & & & & & & \\
\hline Low $(\leqslant 0.3)$ & $11 / 13$ & 1.09 & 0.43 to 2.77 & $10 / 13$ & 1.98 & 0.73 to 5.37 \\
\hline High $(>0.3)$ & $13 / 8$ & 1.37 & 0.50 to 3.81 & $9 / 8$ & 1.24 & 0.38 to 4.05 \\
\hline Coal dust : $_{\text {: }}$ & & & & & & \\
\hline Never exposed & $254 / 270$ & 1.00 & - & $163 / 270$ & 1.00 & - \\
\hline Ever exposed & $42 / 26$ & 1.67 & 0.92 to 3.02 & $38 / 26$ & 2.31 & 1.21 to 4.40 \\
\hline Probability of exposure (\% & & & & & & \\
\hline$\leqslant 90$ & $22 / 13$ & 1.62 & 0.75 to 3.46 & $19 / 13$ & 1.83 & 0.80 to 4.17 \\
\hline$>90$ & $20 / 13$ & 1.75 & 0.75 to 4.08 & $19 / 13$ & 3.12 & 1.22 to 8.01 \\
\hline Duration of exposure (y): & & & & & & \\
\hline$<6$ & $15 / 7$ & 2.12 & 0.79 to 5.65 & $12 / 7$ & 2.39 & 0.81 to 6.99 \\
\hline $6-20$ & $10 / 7$ & 1.44 & 0.48 to 4.31 & $15 / 7$ & 2.18 & 0.75 to 6.32 \\
\hline$>20$ & $17 / 12$ & 1.52 & 0.64 to 3.58 & $11 / 12$ & 2.37 & 0.86 to 6.52 \\
\hline Cumulative level: & & & & & & \\
\hline Low $(<0.25)$ & $14 / 9$ & 1.70 & 0.68 to 4.25 & $13 / 9$ & 1.58 & 0.58 to 4.31 \\
\hline Medium $(0.25-25)$ & $13 / 8$ & 1.54 & 0.27 to 4.15 & $11 / 8$ & 2.28 & 0.80 to 6.50 \\
\hline High $(>25)$ & $15 / 9$ & 1.78 & 0.66 to 4.78 & $14 / 9$ & 3.73 & 1.23 to 11.3 \\
\hline Silica dust ${ }^{\star \star}$ : & & & & & & \\
\hline Never exposed & $173 / 181$ & 1.00 & - & $113 / 181$ & 1.00 & - \\
\hline Ever exposed & $123 / 115$ & 0.96 & 0.65 to 1.40 & $88 / 115$ & 0.81 & 0.50 to 1.31 \\
\hline Probability of exposure $(\%$ & & & & & & \\
\hline$<10$ & $56 / 64$ & 0.87 & 0.55 to 1.38 & $44 / 64$ & 0.93 & 0.53 to 1.62 \\
\hline $10-90$ & $29 / 24$ & 0.97 & 0.51 to 1.87 & $16 / 24$ & 0.45 & 0.20 to 1.01 \\
\hline$>90$ & $38 / 27$ & 1.23 & 0.62 to 2.44 & $28 / 27$ & 0.98 & 0.43 to 2.20 \\
\hline Duration of exposure (y): & & & & & & \\
\hline$<7$ & $29 / 32$ & 0.70 & 0.38 to 1.30 & $24 / 32$ & 0.76 & 0.37 to 1.56 \\
\hline $7-20$ & $35 / 24$ & 1.46 & 0.78 to 2.74 & $24 / 24$ & 0.97 & 0.45 to 2.06 \\
\hline $21-36$ & $29 / 30$ & 0.74 & 0.39 to 1.40 & $21 / 30$ & 0.65 & 0.30 to 1.40 \\
\hline$>36$ & $30 / 29$ & 1.07 & 0.57 to 1.99 & $19 / 29$ & 0.87 & 0.41 to 1.87 \\
\hline Cumulative level: & & & & & & \\
\hline Very low $(<0.004)$ & $22 / 29$ & 0.71 & 0.37 to 1.36 & $26 / 29$ & 1.11 & 0.55 to 2.23 \\
\hline Low $(0.004-0.011)$ & $31 / 30$ & 0.97 & 0.53 to 1.78 & $21 / 30$ & 0.88 & 0.42 to 1.84 \\
\hline Medium $(0.012-0.100)$ & $38 / 32$ & 1.18 & 0.67 to 2.08 & $18 / 32$ & 0.54 & 0.25 to 1.14 \\
\hline High $(>0.100)$ & $32 / 24$ & 0.95 & 0.45 to 2.01 & $23 / 24$ & 0.73 & 0.31 to 1.76 \\
\hline
\end{tabular}

ORs adjusted for age, smoking, and alcohol (see text).

*Also adjusted for exposure to formaldehyde (yes/no) and mineral fibres (yes/no) for the larynx, and for exposure to formaldehyde (yes/no) , mineral fibres (yes/no) and asbestos (yes/no) for the hypopharynx.

†Also adjusted for exposure to coal dust (yes/no) for the larynx, and for exposure to coal dust (yes/no) and asbestos (yes/no) for the hypopharynx.

$\ddagger$ Also adjusted for exposure to formaldehyde (yes/no) for the larynx and hypopharynx.

\Also adjusted for exposure to formaldehyde (yes/no) and asbestos (yes/no) for the hypopharynx only.

ๆAlso adjusted for exposure to formaldehyde (yes/no) for the larynx and hypopharynx

${ }^{\star \star}$ Also adjusted for exposure to coal dust (yes/no) for the larynx, and for exposure to coal dust (yes/no), asbestos (yes/no), and education level (only primary school or more) for the hypopharynx. 
Table 4 Risk of cancer of the larynx and hypopharynx, associated with occupational exposure to formaldehyde and coal dust after excluding subjects with a probability of exposure $<10 \%$

\begin{tabular}{|c|c|c|c|c|c|c|}
\hline & \multicolumn{3}{|l|}{ Larynx } & \multicolumn{3}{|c|}{ Hypopharynx } \\
\hline & $\begin{array}{l}\text { Cases/ } \\
\text { controls }\end{array}$ & $\begin{array}{l}\text { Adjusted } \\
\text { OR }\end{array}$ & $95 \% C I$ & $\begin{array}{l}\text { Cases/ } \\
\text { controls }\end{array}$ & $\begin{array}{l}\text { Adjusted } \\
\text { OR }\end{array}$ & $95 \% C I$ \\
\hline \multicolumn{7}{|l|}{ Formaldehyde: } \\
\hline Never exposed & $194 / 211$ & 1.00 & - & $118 / 211$ & 1.00 & - \\
\hline Ever exposed & $44 / 35$ & 1.17 & $0.63-2.17$ & $41 / 35$ & 1.74 & $0.91-3.34$ \\
\hline \multicolumn{7}{|c|}{ Duration of exposure (y): } \\
\hline$\leqslant 7$ & $15 / 7$ & 1.68 & $0.60-4.72$ & $6 / 7$ & 0.74 & $0.20-2.68$ \\
\hline $7-20$ & $14 / 12$ & 0.86 & $0.33-2.24$ & $19 / 12$ & 1.65 & $0.67-4.08$ \\
\hline$>20$ & $15 / 16$ & 1.14 & $0.47-2.74$ & $16 / 16$ & 2.70 & $1.08-6.73$ \\
\hline \multicolumn{7}{|c|}{ Cumulative level: } \\
\hline Low & $4 / 2$ & 0.68 & $0.12-3.90$ & $3 / 2$ & 0.78 & $0.11-5.45$ \\
\hline Medium & $17 / 11$ & 1.86 & $0.76-4.55$ & $13 / 11$ & 1.77 & $0.65-4.78$ \\
\hline High & $23 / 22$ & 0.91 & $0.42-1.99$ & $25 / 22$ & 1.92 & $0.86-4.32$ \\
\hline \multicolumn{7}{|l|}{ Coal dust: } \\
\hline Never exposed & $254 / 270$ & 1.00 & - & $163 / 270$ & 1.00 & - \\
\hline Ever exposed & $27 / 16$ & 1.70 & $0.80-3.59$ & $23 / 16$ & 2.71 & $1.18-6.23$ \\
\hline \multicolumn{7}{|c|}{ Duration of exposure (y): } \\
\hline$<6$ & $8 / 3$ & 2.25 & $0.53-9.51$ & $6 / 3$ & 3.45 & $0.77-15.5$ \\
\hline $6-20$ & $6 / 4$ & 1.28 & $0.28-5.38$ & $7 / 4$ & 1.34 & $0.29-6.06$ \\
\hline$>20$ & $13 / 9$ & 1.65 & $0.61-4.48$ & $10 / 9$ & 3.31 & $1.05-10.3$ \\
\hline \multicolumn{7}{|c|}{ Cumulative level: } \\
\hline Low & $1 / 0$ & - & - & $0 / 0$ & - & - \\
\hline Medium & $11 / 7$ & 1.51 & $0.52-4.44$ & $9 / 7$ & 2.07 & $0.66-6.55$ \\
\hline High & $15 / 9$ & 1.78 & $0.66-4.82$ & $14 / 9$ & 3.44 & $1.13-10.4$ \\
\hline
\end{tabular}

${ }^{\star}$ For each substance, adjustments used in table 3 were kept in the present analysis.

risk increased with cumulative level of exposure $(\mathrm{p}<0.02)$. Exposure to coal dust seemed also to increase the risk of laryngeal cancer, but there was no dose response trend based on cumulative level or duration of exposure.

For the other substances, exclusion of subjects with a low probability of exposure changed the ORs only marginally (data not shown).

The ORs for cancers of the hypopharynx, epilarynx, and endolarynx (larynx without epilarynx) are presented in table 5. Risks for epilaryngeal cancer ran roughly between those for endolaryngeal and hypopharyngeal cancers, and the risks for each substance did not differ much between subsites. The analysis by detailed anatomical subsites of the larynx and hypopharynx gave neither significant nor consistent results (data not shown).

Introducing an induction time $(5,10$, or 15 years) did not substantially change the results, as most exposures had started at the beginning of the working life.

\section{Discussion}

We found a possible association between exposure to formaldehyde and hypopharyngeal cancer, with a dose-response pattern for probability of exposure. After excluding subjects with a low probability of exposure, the risk increased with duration and cumulative level of exposure.
Although some studies of nasopharyngeal cancer have found associations with exposure to formaldehyde, ${ }^{30}{ }^{31}$ most studies of oropharyngeal and hypopharyngeal cancers have not detected such an association. ${ }^{32-36}$ However, many studies consider cancers of the hypopharynx together with those of the oropharynx and even the oral cavity; such a procedure prevents direct comparisons with our data.

No association was found between formaldehyde and laryngeal cancer, although there was an indication of an increased risk among heavy drinkers. However, no dose-response pattern was found, nor was support for an association provided by the analysis that excluded subjects with a low probability of exposure. Although Berrino et $a l^{37}$ found a significantly increased risk for laryngeal cancer, no other studies confirm these results. ${ }^{35} 38$

Exposure to coal dust was associated with a significantly increased risk of hypopharyngeal cancer, and the risk increased with cumulative level and probability of exposure. A significant association between exposure to coal dust and laryngeal cancer was also reported in China. ${ }^{39}$ Haguenoer et $a l^{7}$ found an increased risk of laryngeal but not pharyngeal cancer among coal miners. In our study, the association is limited to the hypopharynx, although nonsignificantly increased risks were found for the larynx. Exposure to coal dust might explain the significantly higher risk of laryngeal and hypopharyngeal cancer (combined) found among coal miners in a previous analysis of the same data. ${ }^{25} \mathrm{~A}$ possible role of exposure to silica dust was also considered, but in the present study no association with exposure to silica was found. The few studies dealing with these cancers and occupational exposure to silica ${ }^{39-41}$ also failed to show any significant association, although Puntoni et $a l^{42}$ found an increased risk of laryngeal cancers among subjects with silicosis.

No detailed analysis could be performed for leather dust, in view of the few exposed subjects. Similarly, the failure to find any significant associations with dust from flour, textiles, and wood may be due to their relatively low frequencies: the possibility of moderately increased risk cannot be ruled out.

To our knowledge, no epidemiological study has examined exposure to flour dust as a risk factor for laryngeal or pharyngeal cancer. Previous epidemiological studies on these cancer sites and occupational exposures to wood dust or textile dust have found no consistent results. Results about exposure to wood dust have been

Table 5 Risk of cancer of the endolarynx, epilarynx, and hypopharynx, by being ever exposed to each substance

\begin{tabular}{|c|c|c|c|c|c|c|c|c|c|}
\hline & \multicolumn{3}{|c|}{ Endolarynx } & \multicolumn{3}{|c|}{ Epilarynx } & \multicolumn{3}{|c|}{ Hypopharynx } \\
\hline & $n$ & $\begin{array}{l}\text { Adjusted } \\
\text { OR }\end{array}$ & $95 \% C I$ & $n$ & $\begin{array}{l}\text { Adjusted } \\
\text { OR }\end{array}$ & $95 \% C I$ & $n$ & $\begin{array}{l}\text { Adjusted } \\
\text { OR }\end{array}$ & $95 \% C I$ \\
\hline Wood dust & 32 & 1.12 & 0.62 to 2.03 & 15 & 0.81 & 0.38 to 1.75 & 33 & 0.89 & 0.47 to 1.68 \\
\hline Formaldehyde & 65 & 1.07 & 0.69 to 1.66 & 37 & 1.25 & 0.71 to 2.19 & 83 & 1.35 & 0.86 to 2.14 \\
\hline Textile dust & 16 & 1.19 & 0.50 to 3.57 & 8 & 1.33 & 0.56 to 2.54 & 19 & 1.63 & 0.74 to 3.60 \\
\hline Flour dust & 15 & 1.43 & 0.62 to 3.44 & 7 & 1.60 & 0.53 to 4.77 & 21 & 1.92 & 0.82 to 4.50 \\
\hline Coal dust & 26 & 1.40 & 0.73 to 2.68 & 16 & 2.06 & 0.93 to 4.60 & 38 & 2.31 & 1.21 to 4.40 \\
\hline Silica dust & 75 & 0.83 & 0.54 to 1.27 & 48 & 1.18 & 0.69 to 2.03 & 88 & 0.81 & 0.50 to 1.31 \\
\hline
\end{tabular}

^For each substance, adjustments used in table 3 were kept in the present analysis. 
discordant as to laryngeal $1^{13^{13-45}}$ and oropharyngeal and hypopharyngeal ${ }^{7546}$ cancers. Similarly, although some authors have found an increased risk of laryngeal or pharyngeal cancers among textile workers, ${ }^{7-9} 47$ other studies have failed to confirm these results. ${ }^{13} 353948$ Moreover, most textile or wood workers are exposed not only to wood dust or textile dust, but also to numerous other substances, including solvents, varnishes, dyes, asbestos, and formaldehyde. ${ }^{37450}$ These other substances can all be potential confounders in studies based on job titles.

Our study has several limitations. Controls were recruited during a longer period than the cases, but controls diagnosed in 1987-8 were similar to those recruited in 1989-91 (period of cases recruitment) for the number of jobs, the level of education, the consumption of alcohol and tobacco, and the frequency of occupational exposures.

Interviewers were aware of case-control status, which could introduce a bias. However, they were blind to the study hypotheses and comparisons between interviewers concerning the main characteristics of the subjects did not show important differences. This suggests that an interviewer bias is probably not a major limitation in this study.

The use of a cancer control group limits a possible recall bias. On the other hand, some cancer sites among controls may be associated with the occupational exposures under study. As the proportion of each cancer site was limited, it is unlikely that such associations seriously biased the results. Furthermore, the proportion of exposed subjects did not differ between the sites, for all the substances studied.

The occupational exposures were assessed with a JEM, which could have entailed non-differential misclassification and biased the ORs towards unity. Such non-differential misclassification may also be responsible for the lack of a dose-response pattern in our data. Dosemici et $a \tilde{l}^{11}$ showed that in some situations non-differential misclassification when exposure is assessed by polytomous variables can bias the ORs estimated for intermediate levels away from the null and invert the slope of the dose-response trend. Furthermore, the few subjects with high levels of exposure may be responsible for some negative results.

The few subjects exposed to some substances also necessitated a broad categorisation of the confounders, but as a more stringent control for age, alcohol, and smoking did not affect the ORs substantially, there is probably no important residual confounding.

In this study, we could not consider the impact of some substances known or suspected to be carcinogenic to the larynx and pharynxsuch as sulphuric acid and polycyclic aromatic hydrocarbons. Future work will expand exposure assessment to other substances.

On the whole, our data suggest an association between hypopharyngeal cancer and exposure to formaldehyde and coal dust. Further epidemiological investigations are required for confirmation.
1 International Agency for Research on Cancer. Cancer incidence in five continents. Lyon: IARC, 1997.

2 Elwood JM, Pearson JC, Skippen DH, et al. Alcohol, smoking, social and occupational factors in the aetiology of cancer of the oral cavity, pharynx and larynx. Int $\mathcal{F}$ Cancer 1984;15:603-12.

3 Rothman KJ, Cann CI, Flanders D, et al. Epidemiology of laryngeal cancer. Epidemiol Rev 1980;2:195-209.

4 Tuyns AJ, Esteve J, Raymond L, et al. Cancer of the larynx/ hypopharynx, tobacco and alcohol: IARC: international case control study in Varese (Italy), Zaragoza and Navarra (Spain), Geneva (Switzerland) and Calvados (France). Int f Cancer 1988;41:483-91.

5 Guénel P, Chastang JF, Luce D, et al. A study of the interaction of alcohol drinking and tobacco smoking among French cases of laryngeal cancer. $\mathcal{F}$ Epidemiol Community Health 1988;42:350-4.

6 Riboli E, Kaaks R, Esteve J. Nutrition and oral cancer. Cancer Causes Control 1996; 7:147-56.

7 Haguenoer JM, Cordier S, Morel C, et al. Occupational risk factors for upper respiratory tract and upper digestive tract cancer. Br f Ind Med 1990;47:380-3.

8 Flanders WB, Cann CI, Rothman KJ, et al. Work related risk factors for laryngeal cancer. Am f Epidemiol 1984;119:23-32.

9 Ahrens W, Jockel KH, Patzak W, et al. Alcohol, smoking and occupational factors in cancer of the larynx: a case control study. Am F Ind Med 1991;20:477-93.

10 Burch JD, Howe GR, Miller AB, et al. Tobacco alcohol asbestos and nickel in the aetiology of cancer of larynx: a case control study. F Natl Cancer Inst 1981;67:1219-24.

11 Flanders WD, Rothman KJ. Occupational risk for laryngeal cancer. Am f Public Health 1982;72:369-72.

12 Guénel P, Engholm G, Lynge E. Laryngeal cancer in Denmark: a nationwide longitudinal study based on register linkage data. Br f Ind Med 1990;47:473-9.

13 Zagraniski RT, Kesley JL, Walter SD. Occupational risk facZagraniski RT, Kesley JL, Walter SD. Occupational risk fac-
tors for laryngeal carcinoma: Connecticut 1975-80. Am 7 tors for laryngeal carcinoma:
Epidemiol 1986;124:67-76.

14 Chan CK, Gee JBL. Asbestos exposure and laryngeal cancer: an analysis of the epidemiologic evidence. $\mathcal{F}$ Occup Med 1988;30:23-7.

15 Edelman DA. Laryngeal cancer and occupational exposure to asbestos. Int Arch Occup Environ Health 1989;61:223-7. 6 Liddell FDK. Laryngeal cancer and asbestos. Br f Ind Med 1990;47:289-91.

17 Parnes SM. Asbestos and cancer of the larynx: is there a relationship. Laryngoscope 1990;100:254-61.

18 Smith AH, Handley MA, Wood R. Epidemiological evidence indicates asbestos causes laryngeal cancer. $\mathcal{f}$ Occup Med 1990;32:499-507.

19 Kraus T, Drexler H, Weber A, et al. The association of occupational asbestos dust exposure and laryngeal carcinoma. pational asbestos dust exposure
Isr $7 \mathrm{Med}$ Sci $1995 ; 31: 540-8$.

20 Boffetta P, Jourenkova N, Gustavsson P. Cancer risk from occupational and environmental exposure to polycyclic aromatic hydrocarbons. Cancer Causes Control 1997;8:444-72.

21 Soskolne CL, Zeighami EA, Hanis NM, et al. Laryngeal cancer and occupational exposure to sulfuric acid. Am $\mathcal{F}$ Epidemiol 1984;120:358-69.

22 Soskolne CL, Jhangri GS, Siemiatycki J, et al. Occupational exposure to sulfuric acid in southern Ontario, Canada, in association with laryngeal cancer. Scand $\mathcal{f}$ Work Environ Health 1992;18:225-32.

23 Steenland K. Laryngeal cancer incidence among workers exposed to acid mists (United States). Cancer Causes Control 1997;8:34-8.

24 International Agency for Research on Cancer. Wood dust and formaldehyde. Lyon: IARC, 1995;62:1-440

25 Goldberg P, Leclerc A, Luce D, et al. Laryngeal and hypopharyngeal cancer and occupation: results of a case control study. Occup Environ Med 1997;54:477-82.

26 Marchand JL, Luce D, Leclerc A, et al. Laryngeal and hypopharyngeal cancer and occupational exposure to asbestos and man-made vitreous fibers: results of a case-control study. Am F Ind Med 2000;37:581-9.

27 International Labour Office. International standard classification of occupations. Geneva: International Labour Office, 1968.

28 United Nations Statistical Office. International standard industrial classification of all economic activities. New York: United Nations Statistical Office, 1968.

29 Demers PA, Kogevinas M, Boffetta P, et al. Wood dust and sinonasal cancer: pooled reanalysis of twelve case control studies. Am F Ind Med 1995;28:151-66.

30 Roush GC, Walrath J, Stayner LT, et al. Nasopharyngeal cancer, sinonasal cancer and occupation related to 1987;79:1221-4.

31 West S, Hildesheim A, Dosemeci M. Non-viral risk factors for nasopharyngeal carcinoma in the Philippines: results from a case control study. Int $\mathcal{F}$ Cancer 1993;55:722-7.

32 Blair A, Stewart PA, O’Berg M, et al. Mortality among industrial workers exposed to formaldehyde. $\mathcal{F}$ Natl Cancer Inst 1986;76:1071-84.

33 Merletti F, Boffetta P, Ferro G, et al. Occupational cancer of the oral cavity or oropharynx in Turin Italy. Scand $\mathcal{F}$ Work Environ Health 1991;17:248-54.

34 Vaughan TL, Strader C, Davis C, et al. Formaldehyde and cancers of the pharynx, sinus and nasal cavity: cancers of the pharynx, sinus and nasal cavity:

35 Gustavsson P, Jakobsson R, Johansson $\mathrm{H}$, et al. Occupational exposures and squamous cell carcinoma of the oral cavity, pharynx, larynx and oesophagus: a case-control study in Sweden. Occup Environ Med 1998;55:393-400. 
36 Stayner LT, Elliot L, Blade L, et al. A retrospective cohort Stayner LT, Elliot L, Blade L, et al. A retrospective cohort mortality study of workers exposed to formaldehyde
garment industry. Am ₹ Ind Med 1988;13:667-81.

37 Berrino F. Occupational factors of upper respiratory tract cancers. In: Hirsch A, Goldberg M, Martin JP, et al, eds. Prevention of respiratory diseases. New York: Marcel Dekker, 1993;81-96

38 Wortley P, Vaughan TL, Davis S, et al. A case control study of occupational risk factors for laryngeal cancer. Br $\mathcal{F}$ Ind Med 1992;49:837-44

39 Zheng W, Blot WJ, Shu XO, et al. Diet and other risks factors for laryngeal cancer in Shangai. Am f Epidemiol 1992; 136:178-91.

40 Bravo MP, Espinosa J, Calero JR. Occupational risk factors for cancer of the larynx in Spain. Neoplasma 1990;37:47781.

41 Andjelkovitch DA, Janszen DB, Brown MH, et al. Mortality of iron foundry workers: IV analysis of a subcohort exposed
to formaldehyde. $\mathcal{F}$ Occup Environ Med 1995;37:826-37.

42 Puntoni R, Goldsmith DF, Valerio F, et al. A cohort study of workers employed in a refractory brick plant. Tumori 1988 74:27-33.

43 Wynder EL, Covey LS, Mabuchi K, et al. Environmental factors in cancer of the larynx: a second look. Cancer 1976 38:1591-601
44 Vaughan TL, Davis S. Wood dust exposure and squamous cell cancers of the upper respiratory tract. Am $\mathcal{F}$ Epidemiol 1991;133:560-4.

45 Brown LM, Mason TJ, Pickle LW, et al. Occupational risk factors for laryngeal cancer on the Texas Gulf Coast. Cancer Res 1988;48:1960-4.

46 Huebner WW, Schoenberg JB, Kesley JL, et al. Oral and pharyngeal cancer and occupation: a case control study. Epidemiology 1992;3:300-9.

47 Moss E, Lee WR. Occurrence of oral and pharyngeal cancers in textile workers. Br f Ind Med 1974;31:22432 .

48 Whitaker CJ, Moss E, Lee WR, et al. Oral and pharyngeal cancer in the North-west and West Yorkshire regions of England, and occupation. Br f Ind Med 1979;36:292-8.

49 Nylander LA. Carcinogenic effects of wood dust: review and discussion. Am f Ind Med 1993;24:619-47.

50 Kauppinen TP, Partanen TJ, Hernberg SG, et al. Chemical exposures and respiratory cancer among Finnish woodworkers. Br f Ind Med 1993;50:143-8.

51 Dosemeci M, Waldocher S, Lubin JH. Does non-differential misclassification of exposure always bias a true effect toward the null value ? Am f Epidemiol 1990;132:746-8.

\section{Correspondence and editorials}

Occupational and Environmental Medicine welcomes correspondence relating to any of the material appearing in the journal. Results from preliminary or small scale studies may also be published in the correspondence column if this seems appropriate. Letters should be not more than 500 words in length and contain a minimum of references. Tables and figures should be kept to an absolute minimum. Letters are accepted on the understanding that they be subject to editorial revision and shortening.

The journal also publishes editorials which are normally specially commissioned. The Editor welcomes suggestions regarding suitable topics; those wishing to submit an editorial, however, should do so only after discussion with the Editor. 